\title{
The Impact of Introducing Therapeutic Robots in Hospital's Organization
}

\author{
Cecilia Yu Chung Chang, Marta Díaz, and Cecilio Angulo* \\ CETpD. Centre Estudis Tecnòlogics atenció Dependència i Vida Autònoma \\ UPC. Universitat Politècnica de Catalunya · BarcelonaTech \\ 08800 Vilanova i la Geltrú, Spain \\ ceciliayu.chung@alumni.esade.edu, \{marta.diaz, cecilio.angulo\}@upc.edu \\ http://www.upc.edu/cetpd
}

\begin{abstract}
The introduction of robots in health and wellbeing services could mean a great improvement in patients' life, but also implies a huge change in hospital's organization. This work introduces a empirical study that investigates the factors influencing the process of adoption of robots in hospitals. Interviews have been completed in a health organization leading this change. Learned lessons lead to define a balance of facilitators and barriers that should help to apply the innovation. This process has been completed from Kotter's leading change approach, since it would be the roadmap for the whole procedure.
\end{abstract}

Keywords: technological change, therapeutic robot, hospital.

\section{Introduction}

The introduction of robots in health and wellbeing services could mean a great improvement in users' life, and there is a great amount of investigation related to this topics. Their introduction implies a huge change not only in the patient's personal life, but also in the way doctors, nurses, therapists and psychologists work. The impact in the first group of people's life is clear and has been documented in several papers, but the impact of robotics in the workplace is not well stablished yet.

Craig Brod defines technostress [2] as "a modern disease of adaptation caused by an inability to cope with the new computer technologies in a healthy manner". It could happen in two types of people: the ones who do not want to accept computer technology, and the ones who over-identificates with it. This work introduces a empirical study that investigates the factors influencing the process of adoption of robots in hospitals. It expands the topic of robotics from a management - human resources point of view [7] by using Kotter's Leading Change theory 4. Factors influencing this adaption/rejection are firstly studied based on interviews with professionals leading this change in a real institution (Kotter's approach was not employed), then facilitators and barriers are defined from learned lessons. Finally, some conclusions and future work lines are summarized.

\footnotetext{
* Research supported by the Spanish Ministry of Science and Education through the project SOFIA (TIN2011-28854-C03-01,03).
}

J. Bravo, R. Hervás, and M. Rodríguez (Eds.): IWAAL 2012, LNCS 7657, pp. 312-315, 2012.

(C) Springer-Verlag Berlin Heidelberg 2012 


\section{Introducing a Technological Change}

It is reported in [5] that the introduction of computers in the workplace did have an effect of stress among $18 \%$ workers because of the need of learning a new skill. On the other hand, computers at work also contributed to make it more interesting, as $60 \%$ of the people stated. An even more curious figure is that only a $4 \%$ thought computers made work less interesting. Lessons learned from this kind of studies can be easily linked with the Kotter's theory about Leading Change [4]. Accordingly, a number of steps are recommended and required in order to manage changes and transformations in an organization: (1) Establish a sense of urgency; (2) Form a powerful guiding coalition; (3) Create a vision; (4) Communicate the vision; (5) Empower others to act on the vision; (6) Plan for and create short-term wins; (7) Consolidate improvements and produce more change; and (8) Institutionalize new approaches.

In order to apply the Kotter's theory to the introduction of robotics in hospitals, this study investigates the factors that could influence in its adaptation or rejection. Initial hypothesis will be set about facilitators and barriers to adopting robots in the organization [1, then they will be checked and revisited after having interviews with different profiles of professionals.

\section{$3 \quad$ Methodology}

For this study, information about introducing robotics in hospitals have been collected based on the Technology Adoption Model approach [3. The main instruments used were interviews of 45 minutes long and semi-open questions on different topics related to the introduction of robotics in a hospital. Participants were professionals recruited from the Hospital Sant Joan de Déu (HSJD), Barcelona, Spain. Interviewed people were four: a doctor from the Research and Innovation Department; two professionals from the Psychology Department were also asked for support through interviews on their opinions towards the introduction of robots at their workplace; finally, a doctor of the Pediatric department was also interviewed.

\subsection{Revisiting Facilitators and Barriers}

Some phases were completed in the HSJD before starting experimentation with robots. In the first place, they read a lot about robotics therapeutic applications until they decided to give it a chance. Next, it was important to determine which kind of robot and what department of the hospital were going to be selected. Taking this consideration into account, robots were finally introduced in the Psychology department with the treatment of children with autism, cerebral deficit, and traumatism. In the Director of Innovation's words: "you look for open-minded people, we did not chose any department for using the robot, but the one we knew that would accep it". After three months and several sessions, the group of therapists and engineers were satisfied with the results: the robot 
became a source of motivation for the children, and it also became a catalyst of the relationships between these children, as they had a common interest.

Through the focus groups analyses, we concluded that professionals envisaged two conflicting perspectives: on the one hand, professionals would foster the use of robotics if they do feel it is useful and benefits patients. On the other hand, the perceived effort related to learning new skills and the fear of depersonalization in the professional-patient relationships leads people to refuse these new technologies. This is one reason why all new changes have to overtake a slower period of adaptation at the beginning, same as with products there is a group called "early adopters". Only those doctors and healthcare professionals who have seen it work before will feel safe and apply robotics with their patients; we can observe that the phase in which we are now is the "early adopters" one.

\subsection{A Modified Balance of Facilitators and Barriers}

Factors were finally grouped in: Usefulness, i.e., how likely the robot will really help the patient and his/her disease, though interviewed professionals agreed they did not expect robots to solve the whole problem. Robots can show emotions depending on their environment, so that they seem to be alive and create more engagement with the child, it is to say, robots enhance the sense of social presence.

Previous success is a second 'in favor' factor. It is important for doctors because it is a risk minimizer. It will be great help if doctors who have experience with robots would write reports or publish articles in specialized magazines so that the medical community would be more used to listen the word "robot" related to their business [6]. This would create a comfort around the topic, and would make inexperienced doctors easier to reach.

The third element is that organization's own vision and values are also critical in anticipating whether it is going to accept robots or not. Hospitals are, in the end, companies, so they have a vision and values that determine its personality.

On the other side, high costs attached to the implementation of robots and their maintenance could make managers and also doctors more reluctant to apply the new technology. This effect can be easily neutralized in the near future, as the utility will counter the costs, and the costs will be lower in any case.

The effort needed for learning new skills is a second adverse factor, because it can also back away the efforts. However, in the case of health practitioners, the lifelong training is naturally accepted as a professional requirement.

The third factor is the fear of depersonalization when using robots with patients. Many professionals guess that using robots will replace, at least in part, their daily visits and direct contact with patients. This barrier is probably the most difficult obstacle to overcome because it is not related to a tangible characteristic of robots, but an intangible idea that many people have in mind.

Finally, there is a lack of people who know about both healthcare and robotics fields. Hence, an implicit difficulty in the introduction of therapeutic robots is the joint work of healthcare professionals together with technicians. Even though the healthcare professional could use the robot, technician help might still be 
needed. A professional both, controlling the robot and studying the patients, is very likely to feel overwhelmed by the activity, as our interviewed psychologist manifested. This fact was initially ignored, as the study was more focused on how professionals should learn the skills needed to work with robots but forgot in part how difficult and important their actual work is.

\section{Conclusions and Further Research}

The introduction of robots in health and wellbeing institutions implies a huge change in these organizations. This work introduces a empirical study that investigates the factors influencing the process of adoption of robots in hospitals. Methodology to obtain this information includes interviews with professionals in a health organization leading this change, the HSJD. Learned lessons from early experiences lead to define a balance of facilitators and barriers thant should help to apply the innovation. This process has been completed from the Kotter's leading change approach. Since the institution is decided to apply therapeutic robots in its daily activity, further research includes to plan a roadmap for the whole procedure.

Acknowledgments. The authors appreciate the collaboration of the professionals interviewed from the Hospital Sant Joan de Déu.

\section{References}

1. BenMessaoud, C., Kharrazi, H., MacDorman, K.F.: Facilitators and barriers to adopting robotic-assisted surgery: Contextualizing the unified theory of acceptance and use of technology. PLoS ONE 6(1), e16395 (2011)

2. Brod, C.: Techno Stress: The Human Cost of the Computer Revolution. AddisonWesley (1984)

3. Díaz, M., Català, A., Font, A., Narvaiza, L., Rodríguez-Molinero, A.: Factors influencing acceptability of ambulatory telemonitoring systems: A qualitative approach of physicians' views as end-users and prescriptors. Gerontechnology 7(2) (2008)

4. Kotter, J.P.: Leading Change: Why Transformation Efforts Fail. Harvard Business Review 37(3), 59-67 (1995)

5. Lin, Z., Popovic, A.: The effects of computers on workplace stress, job security and work interest in canada. Tech. rep., Applied Research Branch, Human Resources Development Canada (2002)

6. Lo, A.C., Guarino, P.D., Richards, L.G., Haselkorn, J.K., Wittenberg, G.F., Federman, D.G., Ringer, R.J., Wagner, T.H., Krebs, H.I., Volpe, B.T., Bever, C.T., Bravata, D.M., Duncan, P.W., Corn, B.H., Maffucci, A.D., Nadeau, S.E., Conroy, S.S., Powell, J.M., Huang, G.D., Peduzzi, P.: Robot-Assisted Therapy for Long-Term Upper-Limb Impairment after Stroke. New England Journal of Medicine 362(19), 1772-1783 (2010)

7. Senge, P., Kleiner, A., Roberts, C., Ross, R., Roth, G., Smith, B., Guman, E.C.: The dance of change: The challenges to sustaining momentum in learning organizations. Performance Improvement 38(5), 55-58 (1999),

http://dx.doi.org/10.1002/pfi.4140380511

